\title{
Estado y transnacionalización en la minería de oro y plata en México
}

\author{
State and Transnationalism in Gold and Silver Mining in Mexico
}

\begin{abstract}
Resumen: El objetivo del artículo consiste en analizar cómo se ha expresado, en concreto, la estrategia de acumulación por despojo para ser altamente redituales a los capitales extranjeros en la minería de cielo abierto de oro y plata. El concepto teórico conceptual de la acumulación por desposesión se ha instrumentado para que las transnacionales del sector minero inviertan en México. El rasgo económico-político que definiría, dicha acumulación por desposesión, es que su instrumentación para llevarse a cabo, necesita obligatoriamente que el Estado y los dueños de capital minero tengan el interés común "contubernio". Estos espacios receptores de capital minero solo se consolidan expropiando el derecho del trabajador de vivir dignamente con un empleo bien remunerado. En palabras de David Harvey, lo que posibilita la acumulación por desposesión es la liberación de un conjunto de activos, incluida la fuerza de trabajo a un coste muy bajo y en algunos casos, casi nulo.
\end{abstract}

Palavras-Chave: Estado. Minería. Acumulación. Transnacionales. Desposesión.

\begin{abstract}
The objective of this article is to analyze how the accumulation by dispossession strategy has been specifically expressed to be highly profitable for foreign capital in open pit gold and silver mining. The theoretical concept of accumulation by dispossession has been implemented so that transnational corporations in the mining sector invest in Mexico. The economic and political factor that would define such accumulation by dispossession is that its implementation necessarily requires that the State and the owners of mining capital have common of collusion. These areas that receive mining capital are only consolidated by expropriating the worker's right to live in dignity with a well-paid job. In the words of David Harvey, what makes accumulation by dispossession possible is the liberation of a set of assets, including the work force at an extremely low cost, and in some cases, almost none.
\end{abstract}

Keywords: State. Mining. Accumulation. Transnational companies. Expropriation.

\footnotetext{
Marco Antonio Merchand Rojas

Doctor en Ciencias Sociales, profesor e investigador titular C Universidad de Guadalajara.

Guadalajara, México.E-mail: merchandrojas@yahoo.com.mx
} 


\section{Introducción}

El capitalismo globalizado territorial, a través de los sucesos de la historia (fordismo y posfordismo), ha construido una división internacional del trabajo y una división territorial de la producción mundial, que determina un rol fundamental para América Latina como proveedora de recursos naturales (agua, suelos, yacimientos minerales e hidrocarburos -recursos estratégicos).

La apropiación de dichos recursos (materias primas) se caracteriza por un coloniaje formal e informal, que impone una lógica de acumulación a través de los mecanismos de la compra, del alquiler o de la concesión. Estos mecanismos utilizados de dominio sobre los Recursos Naturales (RN) se logran gracias a dos protagonistas claves: el Estado Nación y el capital, que configuran espacios y lugares para la explotación de los RN.

Este nuevo paradigma de la actual geografía económica propicia una disputa global por los recursos naturales, siendo este suceso uno de los elementos más importantes de la dinámica del capitalismo contemporáneo para reproducir una lógica de acumulación de América Latina. La dimensión de las reservas de recursos estratégicos que posee América Latina, y por su condición histórica de ser una región exportadora de materias primas (commodities), hace que esta región tenga un alto grado de vulnerabilidad y dependencia de importaciones no solo de los Estados Unidos, sino ahora de la creciente demanda de China como la mayor potencia comercializadora de commodities. Algunos analistas de la geopolítica ven en China una amenaza a la hegemonía de los Estados Unidos en el ámbito mundial, especialmente en el contexto de la crisis económica más reciente en Estados Unidos y Europa. En la esfera económica, la reprimarización de las economías latinoamericanas está vinculada al incremento en la demanda de materias primas, debido al robusto crecimiento económico chino y su peso demográfico. Las empresas chinas han comenzado a invertir fuertemente en las industrias extractivas de América del Sur y sus bienes manufacturados baratos compiten con los producidos en México y América Central.
En general, las economías latinoamericanas han ampliado su frontera extractiva', donde participan activamente las transnacionales. La ocupación de estos espacios locales y/o regionales por parte de estas empresas han afectado profundamente los derechos y los territorios de los pueblos y comunidades indígenas. El Observatorio de multinacionales de américa Latina así lo demuestra por el mapa interactivo y los informes asociados a cada caso, que ha elaborado la Coordinación por los Derechos de los Pueblos Indígenas (Omal, 2015). Hay que recordar que, a mediados de los noventa, se hablaba de deuda ecológica del norte hacia el sur, incluso en La Encíclica del papa Francisco "Laudato Si -sobre el cuidado de la casa común", publicada el 18 de junio de 2015, se señala una verdadera 'deuda ecológica', particularmente entre el norte y el sur, relacionada con desequilibrios comerciales con consecuencias en el ámbito ecológico, así como con el uso desproporcionado de los recursos naturales, llevado a cabo históricamente por algunos países.

La deuda ecológica nacía del comercio ecológicamente desigual, también de la biopiratería. Otros pasivos ambientales (es decir, deudas ecológicas) de los países del norte venían de su producción excesiva de gases de efecto invernadero. ¿Quién debe a quién?, explicando que la obligación de pagar la deuda externa fomentaba las exportaciones de productos primarios abusando más de la naturaleza. La Encíclica afirma el rol crucial de los movimientos populares, organizaciones ambientalistas y otras de la sociedad civil de abajo, a quienes da el crédito de poner sobre las mesas de discusión nacional e internacional los temas de las crisis climática y ambiental. Afirma que los campesinos alimentan a la mayoría de la humanidad,

$1 \quad$ Para intentar una definición comprensible, utilizaremos el término de extractiva cuando nos referimos a aquellas actividades que remueven grandes volúmenes de recursos naturales que no son procesados (o que lo son limitadamente), sobre todo para la exportación. El extractivismo no se limita a los minerales o al petróleo. Hay también extractivismo agrario, forestal e inclusive pesquero. Un error es asumir que el extractivismo existe solo cuando se extraen recursos minerales o hidrocarburíferos. Hay muchas experiencias de prácticas igualmente extractivistas en la explotación de madera o en la agricultura de monocultivo, por ejemplo, sobre el caso del café en Colombia o el banano en Ecuador. 
con muy poca tierra, agua y combustibles, y que, junto a las comunidades indígenas, son los principales actores que mantienen la diversidad biológica y cultural, hechos que definen claves para la sobrevivencia de todos y del planeta.

También la Encíclica censura a los oligopolios alimentarios y la producción de semillas estériles (semillas Terminator), que sancionan a los agricultores a la dependencia. Ratifica que los transgénicos han significado expulsar muchos pequeños agricultores de sus tierras; igualmente, condena la ambición de las empresas mineras y otras que invaden y expulsan a las comunidades de sus territorios, y afirma que la desaparición de una cultura puede ser tanto o más grave que la desaparición de una especie animal o vegetal. La imposición de un estilo hegemónico de vida ligado a un modo de producción puede ser tan dañina como la alteración de los ecosistemas. Es contundente su crítica a la noción dominante de progreso y al paradigma tecnocrático imperante, pero rescata que ciencia y tecnología tienen un papel a jugar "si actúan comprometidamente a favor del bien común y no de las minorías".

Este paradigma tecnocrático, a través de la intensificación en la extracción de los recursos naturales en las últimas décadas, ha ampliado las fronteras y en donde las empresas transnacionales explotan minerales, hidrocarburos, bosques, ríos etc. Esto ha ocasionado crecientes conflictos socio-ambientales, que favorecen una lucha entre territorialidad privatizada y territorialidad de las comunidades.

En las últimas tres décadas y media, se articula a nuevas modalidades de generación y apropiación de riqueza, que le permite a los monopolios y oligopolios transnacionales acceder a fuentes de ganancia extraordinaria: 1) una nueva división internacional del trabajo basada en la configuración de cadenas globales de producción y el uso masivo de fuerza de trabajo barata; 2) la incorporación de la mayoría de los recursos naturales al proceso de valorización de capital, tanto de la litosfera como de la biosfera; 3) la privatización de medios de producción y sectores económicos estratégicos. En otras palabras, esta globalización neoliberal imperante se caracteriza por poseer monopolios - 0 , para ser más puntual, oligopolios- que dominan sectores importantes de la economía, incluyendo las industrias extractivas. Estos oligopolios son, de alguna forma, la expresión de los llamados países desarrollados, que ya no buscan ejercer directamente el control administrativo sobre territorios extranjeros para su explotación exclusiva. Su accionar se ejerce a través de un capital "trasnacionalizado" de creciente de movilidad transfronteriza.

\section{Estado y transnacionalización}

El Estado allana el camino a todo tipo de inversiones a través de las privatizaciones de los activos públicos, que legalmente están a su resguardo. Con el estilo de desarrollo neoliberal, se instrumenta la venta de esos activos (privatizaciones) y se empieza a operar, de esta forma, sobre todo en los países en desarroIlo, una devaluación masiva de sus activos (agua, petróleo, minas, telecomunicaciones, transporte, sistema de provisión social etc.). Estas facilidades que otorga el Estado Federal o local al gran capital para apropiarse de sus espacios productivos tienen el objetivo de reiniciar un nuevo ciclo de capital a partir de la venta de los activos devaluados y así integrar espacios (nuevos mercados) que reproduzcan el capital y amplíen el mercado mundial. No obstante, por más contradictorio que se vea, es la propia necesidad del capital por conquistar nuevos espacios que hace indispensable el papel del Estado para resguardar dichas inversiones.

Las transnacionales canadienses ${ }^{2}$ han contado con condiciones legales y económicas excepcionales que les permiten operar libremente en territorio nacional. Se realizará un examen macro, consistente en explicar cómo los proyectos de explotación, desarrollo y producción de metales por parte de las transnacionales generan condiciones de conflicto económico y social entre los propios concesionarios (empresas) y los pobladores del lugar.

2 "No es una coincidencia que casi $60 \%$ de las compañías mineras del mundo se encuentran cotizando en la Bolsa de Valores de Toronto (tsx) o su afiliada menor, la tsx Venture Exchange (Bolsa de Capital de Riesgo). Como se explica con detalle en el libro de Denault y Sacher (2012), Imperial Canada Inc., Canadá es un verdadero paraíso legal para las compañías mineras y, en particular, la tsx se destaca en el escenario mundial por estar sujeta a normas ambiguas y laxas. Se supone que la Comisión de Valores de Ontario regula a la tsx, sin embargo, en la práctica hace muy poco para controlar operaciones internas y evitar que funcione como un casino" (Darcy Tetreault 2013). 
Este extractivismo se lleva a cabo por firmas transnacionales, que son agentes que no tienen ningún compromiso de generar efectos multiplicadores en el bienestar social, ni por supuesto de arrastrar a los productores locales para que se beneficien de las explotaciones mineras que ellas comandan; al contrario, la lógica de éstas es solo explotar el recurso natural y extraer el máximo beneficio que permita reproducir su capital mundial. Se podría decir que estas explotaciones mineras funcionan todavía como enclaves económicos al servicio exclusivo de sus corporativos ubicados en los países de origen, apropiándose estas empresas de un recurso natural concedido por un Estado que legaliza no solo la explotación del recurso in situ sino también la de la fuerza de trabajo que proviene de las áreas rurales próximas a la mina.

Por otro lado, no cabe duda de que el común denominador de todos los países productores de minerales, desde México hasta la Patagonia, es que todos guardan el mismo patrón respecto a los mecanismos de poder ligados al control del territorio y al recurso natural. Estos países instrumentaron una serie de políticas privatizadoras que estuvieron orientadas hacia los hidrocarburos y, de manera más amplia, hacia la totalidad de los recursos naturales. Así, por ejemplo, a través de diferentes reformas constitucionales y legislativas, las nuevas normas jurídicas institucionalizaron la autoexclusión del Estado como agente productivo y la consecuente exclusividad del sector privado como único actor autorizado a explotar los recursos naturales.

Como lo expresa también Galafassi, G (2006), América Latina se reconvierte una vez más (luego de los fallidos intentos de industrialización y liberación nacional de los '50 y '60) en casi nada más que oferente de espacios y territorios rurales para la extracción de hidrocarburos, minerales, biodiversidad y alimentos bajo la clásica fórmula de la división internacional del trabajo, enunciada oficialmente como el aprovechamiento de las oportunidades en base a las ventajas comparativas.

La falta de participación pública en el proceso de concesionamiento representa para las empresas mineras una de las "ventajas comparativas" que ofrece México.
De hecho, el Banco Mundial ${ }^{3}$ apoya los cambios legislativos necesarios para liberalizar el sector y abrirlo a la inversión extranjera, cambios que impulsaba a través de diversos préstamos al gobierno mexicano. Por supuesto que, al permitirse la viabilidad sobre la explotación indiscriminada del recurso minero, se tuvieron que sentar las bases de un Estado regulador, que implicó la generación de nuevas normas jurídicas que garantizaron la institucionalización de los derechos de las grandes corporaciones, así como la aceptación de la normativa creada en los espacios transnacionales.

Así, los espacios locales con potencial productivo a favor de la IED estarían acotadas en áreas específicas para albergar determinados subsectores (minería, electrodomésticos, automotriz y la producción agrícola más rentable; hortalizas, flores y frutas). Aquí, encontraríamos la configuración de un espacio a través de una red de empresas que tienen que ver más con el mercado y la producción mundializada en otros países que con el mismo país receptor o, en otras palabras, parafraseando a Harvey, D (2003), se efectúa una acumulación por desposesión" a partir del "saqueo" de los recursos naturales y del territorio.

Cabe mencionar que las políticas neoliberales instrumentadas en México desde mediados de los años 1980 e impulsadas con la entrada del Tratado de Libre Comercio de América del Norte (TLCAN) en 1994 han tenido una enorme importancia para las actividades mineras canadienses. Además del debilitamiento de los derechos laborales, el amordazamiento de los movimientos sociales, la mano dura, la militarización y el desplazamiento de comunidades permiten la implementación y la protección de estas corporaciones transnacionales (Merchand, M 2012).

$3 \quad$ "De 1986 a 1990 el Banco Mundial apoyó los programas de ajuste económico de la administración salinista a través de varios préstamos. Uno de ellos resulta fundamental, es el préstamo número 3359 con el que se apoyaba el Proyecto de Reestructuración del Sector Minero. A pesar de que la naturaleza del préstamo lo coloca dentro de la Categoría A según los lineamientos del Banco Mundial, el préstamo fue catalogado dentro de la Categoría $\mathrm{B}$, eliminando así dos requerimientos fundamentales: la evaluación ambiental plena y las garantías de audiencia pública" (Estrada, A y Hofbauer, H 2001: 92). 
La magnitud del giro neoliberal del estado mexicano se vio expresada con la reforma del artículo 27 constitucional, aunada a la expedición de una nueva Ley Agraria, una Ley Minera y una Ley de Inversión Extranjera. La reforma modificaba radicalmente el panorama de la propiedad de la tierra, dándole a los ejidatarios la posibilidad de enajenar su tierra. En 20 años, los gobiernos de Carlos Salinas de Gortari, Ernesto Zedillo Ponce de León, Vicente Fox Quesada y Felipe Calderón Hinojosa otorgaron en concesión 97 millones 800 mil hectáreas a empresas mineras nacionales y extranjeras. La información, obtenida de la Secretaría de Medio Ambiente y Recursos Naturales y del Servicio Geológico Mexicano, describe el incremento del fenómeno, que registró su auge en la administración de Ernesto Zedillo, seguido de Felipe Calderón, Vicente Fox y Carlos Salinas. También, con la información de la Secretaría de Energía -por medio de su Sistema de Administración Minera- se documenta que los principales beneficiarios de la concesión de terrenos en el sector minero nacional son las empresas Peñoles, Grupo México y Frisco.

\section{Territorialización de la minería}

Respecto a la participación de las firmas extranjeras en la explotación minera en México es superior a dos terceras partes del total. De ellas, Canadá participa con 74 por ciento de los proyectos mineros (que representan 207); Estados Unidos, 15 por ciento (43); China, 3 (8); Australia, 2 (6); Japón, 2 (5); otros, 4 por ciento (11). Así, los estados que aportan concesiones a la inversión minera extranjera son: Sonora, 24 por ciento (204 en esa entidad); Chihuahua, 14 por ciento (120); Durango, 11 (97); Sinaloa, 10 (85); Zacatecas, 8 (66); Jalisco, 7 (60); Guerrero, 4 (35); y Oaxaca, 4 por ciento (33). Siguen Nayarit, 3 por ciento (22); Michoacán, 2 (19); San Luis Potosí, 2 (17); Guanajuato, 2 (16);
Colima, uno (11); Coahuila, uno (11); Baja California, uno (11); Puebla, uno (10); Chiapas, uno (7); estado de México, uno (7); Baja California Sur, uno (7); y Querétaro, uno por ciento (5).

Como señala Bebbington (2007), ${ }^{4}$ ya en el período 1990-1997, mientras la inversión en explotación minera en el ámbito mundial creció un 90\%, en América Latina, creció 400\%. En consonancia con ello, durante los años 1990, la mayor parte de los países latinoamericanos involucrados llevó a cabo una profunda reforma del marco regulatorio para conceder amplios beneficios a las grandes empresas transnacionales, que ya venían operando a escala global de hace tiempo. Dichas reformas regulatorias fueron respaldadas por los propios Organismos Internacionales (Banco Mundial, BID, entre otros), a fin de facilitar, promover y garantizar el auge regional de la nueva minería. Pero independientemente del tipo de mineral (metálicos y no metálicos) que se va a extraer, existe un elemento común que les es propio a su explotación y que consiste en que su explotación acarrea una profunda e inevitable actividad destructiva sobre los recursos no renovables directos e indirectos, además de ocasionar impactos de importancia sobre recursos renovables asociados a las zonas donde se ubican los complejos mineros.

Por ejemplo, como bien lo explica Oblasser y Chaparro (2008) respecto a la percepción negativa de la minería, ésta se debe, por un lado, a los impactos y riesgos ambientales irreversibles asociados con la explotación del recurso minero, así como también a los efectos sociales que provoca esta actividad en los pobladores locales. Los más altos índices de pobreza caracterizan a los espacios mineros y confirman que las actividades mineras benefician solo a las empresas mineras, sin lograr un notable y permanente

$4 \quad$ Citado por Svampa y Antonelli (2009). 
crecimiento económico en las zonas afectadas.

Es sabido que la minería es una actividad con una vida útil limitada. El cierre puede ocurrir cuando se agote el mineral buscado o por cuestiones económicas que no permiten hacer redituable su emprendimiento. El cierre de una empresa es el comienzo de una etapa de problemas ambientales con los que se convivirá para siempre, ya que los desperdicios perdurarán en las rocas, en el agua y en el aire (Espinoza, 2004).

Sin embargo, hay que destacar que el tipo de minería (a cielo abierto), diferente de la tradicional, es lo que implica niveles aún mayores de afectación del medio ambiente, generando cuantiosos pasivos ambientales $^{5}$, al tiempo que requiere tanto un uso desmesurado de recursos, entre ellos el agua y la energía, ambos imprescindibles para sus operaciones, como una intervención de manera violenta en la geografía de los territorios para la explotación. En general, en 2010, la situación del sector registró un giro sobresaliente en las producciones de oro, plata, plomo, zinc, molibdeno, fierro, manganeso, fluorita, caolín, fosforita y sulfato de sodio. Igualmente, México se ubicó como el primer destino en América Latina y el cuarto más importante en el ámbito mundial para la inversión minera en explotación, y mantuvo la quinta posición en cuanto a las ventajas para invertir en el sector (González, J 2011).

Sobre el particular, es de tener en cuenta lo señalado en el Informe Anual 2011 de la Cámara Minera de México (CAMIMEX), en el que se establece, entre otras cosas, que el 2010 fue un año relevante para el sector minero nacional, pues las producciones de los principales metales preciosos, metales industriales y no metálicos rompieron récords de extracción,

$5 \quad$ En Chile se entiende, según el proyecto de Ley de la Remediación de Pasivos Ambientales, aquella faena minera abandonada o paralizada, incluyendo sus residuos, que constituye un riesgo significativo para la vida o salud de las personas o para el medio ambiente. En Perú se consideran como Pasivos Ambientales Mineros (PAM) todas aquellas instalaciones, efluentes, emisiones, restos o depósitos de residuos producidos por operaciones mineras actualmente abandonadas o inactivas que constituyen un riesgo permanente y potencial para la salud de la población, el ecosistema circundante y la propiedad (Oblasser y Chaparro, 2008). consolidando a nuestro país como uno de los más importantes en el ámbito mundial. En la perspectiva de la CAMIMEX, este crecimiento permitió que el valor de la producción minero-metalúrgica fuera de 13.9 mil millones de dólares, lo que significa que este sector generó más divisas que la industria turística, la cual sumó 11.8 mil millones de dólares. Además, la Cámara Minera de México destaca que, por tercer año consecutivo, la minería se ubica entre los sectores productivos más importantes de nuestro país y que las divisas generadas por esa industria fueron 51\% superiores a las recibidas en 2009.

Respecto a la operación de las transnacionales en México, el reportaje de Israel Rodríguez (2009), del periódico la Jornada, explica que las empresas mineras de Canadá 6 (con una larga lista de consecuencias sobre el medio ambiente y las comunidades donde operan) poseen más de 70 por ciento de los proyectos de explotación, desarrollo y producción de metales preciosos, como oro y plata, del total de las empresas con capital extranjero que operan en México. Como insiste en explicar Israel Rodríguez, que pese a los efectos devastadores donde operan las empresas canadienses, como en el caso de la Minera San Xavier, en San Luis Potosí, las autoridades esperan que la producción anual global de oro en el país alcance las 70 toneladas, gracias a proyectos como Peñasquito; Zacatecas; Dolores; Pinos Altos; y Palmarejo, en Chihuahua; entre otros, los cuales en su mayoría son realizados por empresas del país de la hoja de maple.

$6 \quad$ "Las compañías mineras canadienses dominan el sector minero a escala mundial. De hecho, tres cuartas partes de las empresas mineras en el mundo tienen sus oficinas centrales en Canadá y casi $60 \%$ están registradas en la Bolsa de Valores de Toronto. Estas compañías representan cerca de $40 \%$ de la inversión mundial en explotación minera en el mundo, con 1,817 proyectos en América Latina y el Caribe (Mining Association of Canada, 2011: 48). América Latina destaca como principal región por la que opta la inversión minera canadiense, quedando África muy atrás en segundo lugar. En efecto, más de la mitad de los activos de las mineras canadienses se ubica en América Latina, con un valor estimado de aproximadamente 57 mil millones de dólares. Compañías como Barrick Gold, Yamana Gold, Goldcorp, Teck, Kinross Gold y Pan American Silver llevan la delantera, cada una de ellas con ingresos anuales por encima de mil millones de dólares por concepto de operaciones en América Latina" (Tetreault, D. 2013). 
También cabe decir que el estado de Chiapas es codiciado por las empresas mineras canadienses. Desde 2003 hasta 2006, el gobierno federal ha otorgado 72 concesiones mineras en Chiapas, que abarcan 727,435 hectáreas. Más de la mitad de estas tierras (419,337 hectáreas) está en manos de dos empresas canadienses: la Linear Gold y la Frontier Development (Group Mandeep, 2007).

Como ya se ha explicado, la presencia de las empresas mineras canadienses en México se debe a la apertura y a la flexibilización de las diversas normas de inversión extranjera después de la entrada en vigor del Tratado de Libre Comercio durante la gestión del entonces presidente Carlos Salinas de Gortari. En 1993 se cambió la Ley Minera, que databa de 1961, y empezó la apertura del sector minero al capital extranjero al eliminar la normatividad que exigía que se asociara con capital nacional en una proporción de 49-51 por ciento (Mandeep, 2007).

Diversos estudios han concluido que en otros países las concesiones mineras se otorgan luego de un largo proceso, que puede tardar entre ocho y diez años, que incluye la realización de audiencias públicas y foros, en los que diversos grupos involucrados con el tema exponen sus puntos de vista con respecto al proyecto. En cambio, en México, el proceso de concesión es cerrado y centralizado, con la competencia del gobierno federal, y se puede resolver en un plazo de solamente ocho meses (Estrada y Hofbauer, 2001).

De acuerdo con información de la Cámara Minera de México, en Argentina, se aplica un impuesto de 3 por ciento a la extracción minera; en Brasil, la tasa varía según el mineral de que se trate, pero va de 2 a 3 por ciento; en Chile, de 0.5 a 5 por ciento; y en Perú, de 1 a 3 por ciento. ¿En México? Cero por ciento; solo la simbólica cuota fija por hectárea. Y por lo que toca a regalías mineras, la base para el reparto es así: Argentina, sobre valor boca mina; Brasil, ingreso neto; Chile, sobre renta gravable con ciertas adiciones y deducciones; Perú, ingresos menos algunos costos de tratamiento. ¿En México? sencillo: cuota por hectárea y consolidación fiscal.

A la fecha, solo subsisten las cuotas referidas, que son simbólicas y no representan un monto importante en la recaudación federal; la base para este derecho (número de hectáreas concesionadas) es una aberración económica, ya que debería ser fijada de acuerdo con el volumen o cantidad de mineral extraído, el cual nada tiene que ver con el número de hectáreas concesionadas 0 asignadas al particular. El texto vigente no considera a los minerales producidos en función a su valor de comercialización, sino solamente a la superficie del terreno sobre el cual se otorga una concesión 0 asignación correspondiente (Rodríguez, I 2009).

De acuerdo con el informe de la Cámara Minera de México, la producción mundial de oro experimentó un ligero descenso de $3.6 \%$ para sumar un total de 2 mil 356 toneladas (76 millones de onzas). Por segundo año consecutivo, China fue el mayor productor, con un total de 288 toneladas, seguido por Estados Unidos, con 234 toneladas y Sudáfrica, con 232 (Sistema Integral de Economía Minera -SINEM- 2008).

En el caso de México, el grupo de metales preciosos se ubicó en el renglón con el mejor comportamiento dentro de la industria minera nacional durante 2008. Por primera vez, el valor de la producción de oro fue superior al valor de la producción de plata, alcanzando 16\% del valor total de la producción minero-metalúrgica del país. La producción minera de oro ascendió a 49.6 toneladas (1 millón 595 mil onzas), lo que representó un crecimiento de $13.6 \%$ con respecto a 2007, y, con ello, se alcanzó un máximo histórico en la producción nacional de este metal, colocando a México en la décima tercera posición como productor mundial de oro.

La mina de oro "Los Filos", en el estado de Guerrero, produjo 213 mil 600 onzas de oro (6.6 toneladas); en tanto, "El Sauzal", en Chihuahua, alcanzó las 274 mil 100 onzas (8.5 toneladas). Sumando las 86 mil 700 onzas de oro producidas en la unidad "Tayoltita" y las 20 mil onzas del proyecto "Peñasquito", que, en mayo de 2008, inició en etapa preoperativa la lixiviación de mineral oxidado, Goldcorp Inc, propietaria de estas cuatro unidades, se convierte en la mayor productora de oro en México, representando 36\% de la producción minera nacional. En el cuadro 1, se muestra la producción de oro por estado y empresa (Rodríguez, I 2009). 
Cuadro 1 - Producción de oro por entidad federativa y empresa.

\begin{tabular}{|l|c|c|c|}
\hline \multicolumn{1}{|c|}{ Localidad } & Empresa & Estado & $\begin{array}{c}\text { Producción } \\
\text { (Onzas) }\end{array}$ \\
\hline El Sauzal & Goldcorp México & Chihuahua & 274,100 \\
\hline La Herradura & Fresnillo Plc & Sonora & 218,700 \\
\hline Los Filos & Goldcorp México & Gucrrcro & 213,600 \\
\hline Ocampo & Gammon Gold & Chihuahua & 154,400 \\
\hline Mulatos & Álamos Gold & Sonora & 151,000 \\
La Ciénega & Fresnillo Plc & Durango & 117,000 \\
\hline Minera San Xavier & New Gold & S.L.P & 86,745 \\
\hline Tayoltita & Goldcorp México & Durango & 86,700 \\
\hline Peñasquito & Goldcorp México & Zacatecas & 20,000 \\
\hline
\end{tabular}

Fuente: Elaboración a partir de http://www.camimex.org.mx/informe/situacion2008.pdf

Os seus sonhos não podem esperar
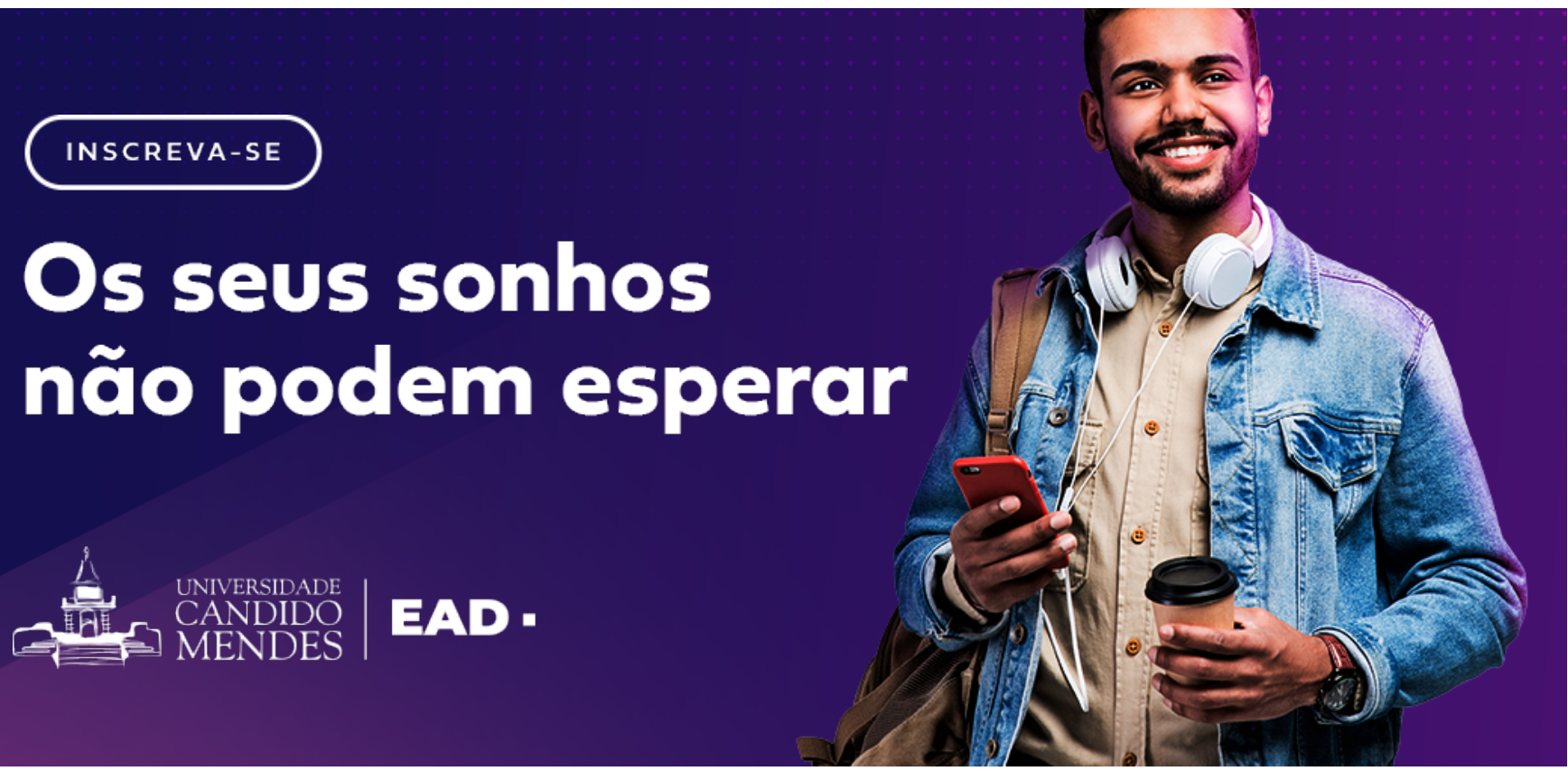
El cuadro 2 permite identificar la cantidad de oro extraído en México entre los años 2000-2010 y confrontar dicha cifra con la extracción de ese metal durante los trescientos años que abarcan toda la época virreinal en nuestro país, -es decir, de inicios del siglo XVI a inicios del siglo XIX. Como es posible apreciar, la cantidad de oro obtenido entre 2000 y 2010 duplica fácilmente el total del metal áureo extraído en los tres siglos de dominación española en México. De las diez minas de oro más grandes en Mé- xico, siete están concesionadas a empresas canadienses: Goldcorp, Agnico Eagle, Alamos Gold, New Gold, Yamana Gold y Torex Gold Resources, con la mayor producción de oro en la mina Peñasquito: 411 mil onzas de producción.

Cuadro 2 - Extracción de oro en México entre 1521-1830 y 2000-2010 (Kilogramos).

\begin{tabular}{|c|c|}
\hline $1521-1830$ & $2000-2010$ \\
\hline 191,825 & 419,097 \\
\hline
\end{tabular}

Fuente: González, J (2011).

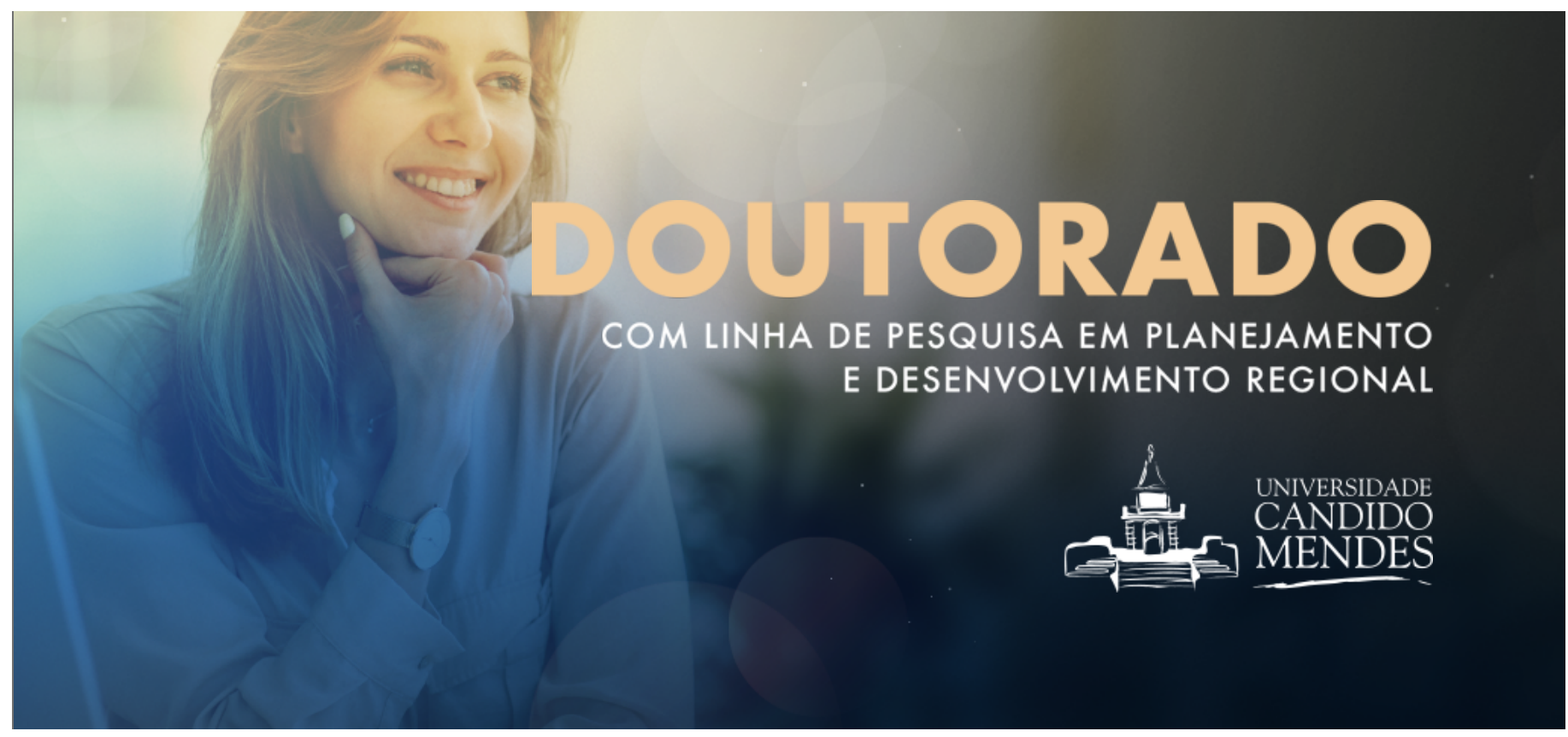


Con relación a la producción de plata, durante 2008 (cuadro 3), la producción mundial fue de 21 mil 63 toneladas (691 millones de onzas), mientras que la producción nacional doméstica alcanzó un récord histórico de 3 mil 241 toneladas (104 millones de onzas), al crecer $3.4 \%$ con respecto al 2007. México mantuvo su posición como el segundo mayor productor de plata en el mundo, inmediatamente después de Perú (3 mil 686 toneladas) y por encima de China. El municipio de "Fresnillo", en Zacatecas, continúa siendo la mina más rica en plata en el mundo. En el periodo, produjo 33 millones de onzas de plata (1 mil toneladas), lo que representa 32.5\% de la producción nacional.

Cuadro 3 - Producción de plata por entidad federativa y empresa.

\begin{tabular}{|l|l|l|l|}
\hline Localidad & Empresa & Estado & Producción (onzas) \\
\hline Fresnillo & Fresnillo Plc. & Zacatecas & $33^{\prime} 000,000$ \\
\hline Álamo Dorado & Pan American Silver & Sonora & $6^{\prime} 900,000$ \\
\hline Ocampo & Gammon Gold & Chihuahua & $5^{\prime} 800,000$ \\
\hline Tayoltita & Goldcorp México & Durango & $5^{\prime} 133,000$ \\
\hline La Colorada & Pan American Silver & Zacatecas & $3^{\prime} 800,000$ \\
Tizapa & Industrias Peñoles & Edo. de México & $3^{\prime} 000,000$ \\
\hline El Herrero & Minas de Bacis & Durango & $2^{\prime} 122,260$ \\
\hline Naica & Industrias Peñoles & Chihuahua & $2^{\prime} 000,000$ \\
Minera San Xavier & New Gold & S.L.P & $1^{\prime} 200,000$ \\
\hline
\end{tabular}

Fuente: Elaboración a partir de http://www.camimex.org.mx/informe/situacion2008.pdf

\section{DOUTORADO \\ COM LINHA DE PESQUISA EM INSTRUMENTOS \\ DE POLÍTICAS PÚBLICAS}


Pero más allá de los datos macro sobre la actividad minera, hay que resaltar la importancia que adquiere esta actividad en las dimensiones más micro. Se puede concluir, como bien lo analizan Kruijt y Vellinga (1983) y aunque este estudio se realizó hace casi 30 años, que las cosas no han cambiado relativamente, pues el fenómeno de las economías enclaves es tan viejo como el proceso de colonización, y nosotros diríamos que es tan actual como el mismo proceso de globalización.
Los casos de la minería, como los de la industria azucarera o las llamadas repúblicas bananeras, es que, en todos los casos, se ha tratado, desde el comienzo, de una relación tensa entre Estado, empresa y trabajadores. La relación tripartita entre las empresas transnacionales, el propio sistema internacional de dependencia y semicolonialismo confirman que el fenómeno es genérico en todos estos tipos de enclaves. La gráfica 1 ilustra bien la situación descrita.

Gráfica 1 - Actores que participan en la actividad minera.

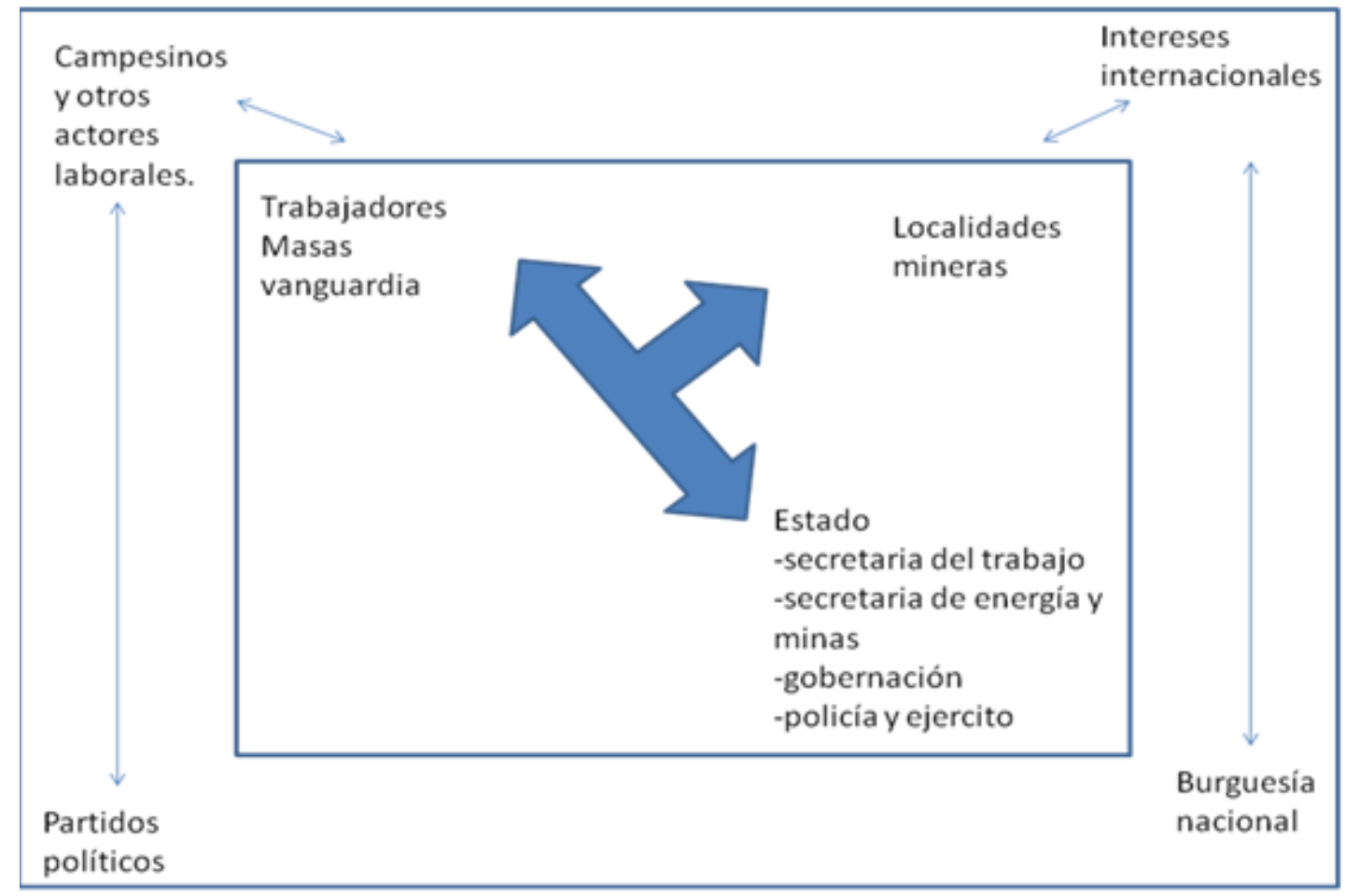

Fuente: Elaboración propia a partir (Kruijt y Vellinga 1983).

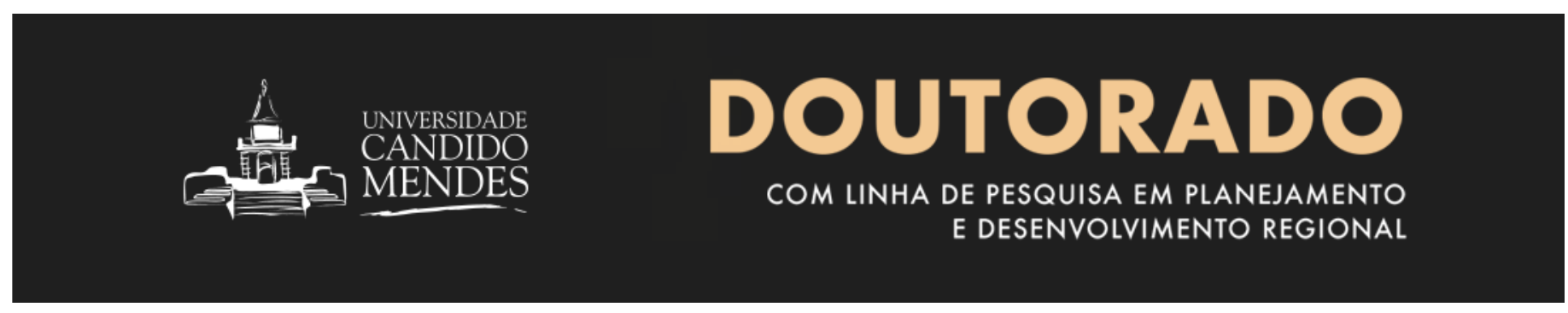


Esta constelación de intereses que se muestran en la gráfica 1, en el cual se pone de manifiesto la relación entre los agentes económicos-políticos que intervienen en el desarrollo de la actividad minera, aunque el estudio de Kruijt y Vellinga (1983) se remite al estudio de la minería en Perú, desde aproximadamente hace treinta años, este gráfica puede aplicarse a otros países con enclaves económicos (Argentina, Bolivia, Chile, Brasil, etc.) y que cumplen con los factores macro. Estos factores han condicionado particularmente la forma concreta de la situación de enclave a la que se refieren Kruijt y Vellinga, y que son el propio desarrollo del mercado mundial y las condiciones locales bajo las cuales se fundó y funciona el enclave que propicia su propia reproducción en tiempo y espacio.

Cabe señalar (González, J 2011) que la próspera situación de los consorcios minero-metalúrgicos en el país, el auge internacional del mercado de metales y el favorable escenario de políticas públicas han propiciado -por ejemploque nunca en la historia de México se haya extraído tanto oro y plata como ahora. Este bonancible entorno cohabita con otras facetas de la minería mexicana contemporánea, la de los accidentes que sepultan a decenas de mineros, la de las difíciles condiciones laborales para amplios porcentajes de trabajadores y la del otorgamiento de enormes concesiones del territorio nacional a empresas mineras que no están sujetas al pago fiscal de regalías.

Como lo explica (Darcy Tetreault 2013), la experiencia de la mina San Xavier de New Gold, en San Luis Potosí, México, es un claro ejemplo que cabe relatar; a partir de los años 1980, se fortalecieron las políticas ambientales mexicanas, por lo menos en el papel, para responder a las críticas en torno a la reestructuración neoliberal. De esta manera, se estableció el marco legal para las accio- nes desarrolladas por el movimiento local de resistencia en San Luis Potosí, que llevó a que el Tribunal Federal de Justicia Fiscal y Administrativa anulara la autorización que la Secretaría del Medio Ambiente y Recursos Naturales (Semarnat) había otorgado a New Gold, con respecto a su evaluación de impacto ambiental. No obstante, New Gold ha logrado continuar con sus actividades extractivistas a cielo abierto, con el apoyo de los altos funcionarios de la Semarnat. Así, a fin de cuentas, en México y en otras partes, el imperativo de la acumulación de capital tiene precedencia sobre las consideraciones ambientales y también sobre la autodeterminación de las comunidades locales.

\section{Conclusiones}

Coincidimos con los comentarios de Darcy Tetreault (2013), quien señala que las compañías mineras canadienses accedan a reservas mineras de bajo costo y mano de obra barata en el sur mundial, donde las regulaciones son laxas o no se hacen cumplir, permitiendo la externalización de los costos ambientales y sociales que en su mayoría pagan las poblaciones rurales pobres que viven cerca de las minas. De esta manera, las mineras canadienses en América Latina reflejan una estrategia imperialista de «acumulación por desposesión». En otras palabras, las ganancias de las compañías mineras canadienses se realizan con altos costos para comunidades locales, campesinos y grupos indígenas, que son desposeídos de sus recursos naturales y paisajes culturales con el fin de abrir camino a las actividades mineras a gran escala. Sin duda, y debido a que las técnicas mineras modernas son altamente destructivas en términos ambientales, tienden a desplazar otras formas de explotación de recursos naturales, incluyendo la agricultura y la ganadería a pequeña escala.
Os seus sonhos não podem esperar 
Al control que ejercen las empresas mineras sobre extensas zonas del territorio nacional, se suman las deplorables condiciones de trabajo que suelen imponer a sus empleados -equiparables a la esclavitud y carentes de mínimas medidas de seguridad-, que es un factor estrechamente relacionado con el desproporcionado margen de ganancias que obtienen de la explotación de yacimientos; la pobreza, el deterioro ambiental; y la descomposición social que provocan en los entornos en que se desarrolla esa actividad, y el ínfimo aporte que realizan al país por la vía fiscal.

Los gobiernos de las tres décadas recientes han defendido las directrices económicas neoliberales: que la conversión del país en un destino atractivo para los capitales foráneos -mediante acciones como la privatización de la propiedad nacional, la apertura indiscriminada de mercados, la desregulación económica y el aniquilamiento de derechos sociales y laboralesderivaría en una importante captación de divisas que permitirían financiar el desarrollo. A la luz de la bonanza económica que han alcanzado las empresas mineras en el país, de la precariedad e incertidumbre que origina entre trabajadores, campesinos, pueblos originarios y población en general, y del persistente saqueo de recursos que representa esa actividad, es que la agenda pública en México es determinada por los intereses privados y trasnacionales, no por la población. 


\section{Bibliografía}

Bebbington, A. (Ed.) (2013). Industrias extractivas, conflicto social y dinámicas institucionales en la región andina. Lima: Instituto de Estudios Peruanos. Cámara Minera de México (2008). http://www.camimex.org.mx/informe/situacion2008.

Carta Encíclica Laudato si del Santo Padre Francisco sobre el cuidado de la casa común. http://w2.vatican.va/content/dam/francesco/pdf/encyclicals/ documents/papa-francesco_20150524_enciclica-laudato-si_sp.

Espinoza, C. (2004). ¿Más valor que el oro? Los movimientos populares en oposición a la minería con cianuro. Theomai, primer semestre, número 009 Universidad Nacional de Quilmes, Argentina.

Estrada, A. y Hofbauer H. (2001). Impactos de la inversión minera canadiense en México. Una primera aproximación. FUNDAR (Centro de análisis de Investigación).

Galafassi, G. (2006): Naturaleza, Sociedad y Alienación. Ciencia y proceso social en la modernidad. Montevideo: Nordan-Comunida.

Garduño, A. (2014). Con Salinas, Zedillo, Fox y Calderón, auge de mineras. La Jornada, Política.

http://www.jornada.unam.mx/ultimas/2015/04/06/con-salinas-zedillo-fox-y-calderon-auge-de-mineras-4535.

Gónzalez, H. (2001). "Las redes transnacionales y las cadenas globales de mercancías: la agricultura de exportación en México". URL: http://alhim. revues.org/document613.

González, J (2011). Minería en México. Referencias generales, régimen fiscal, concesiones y propuestas legislativas. Centro de Estudios sociales y opinión pública.

Harvey, D. (2003). Espacios de esperanza. Madrid, España: Akal.

Kruijt, D. y Vellinga, M. (1983). Estado, clase obrera y empresa transnacional. Siglo XXI Editores.

Mandeep, D. (2007). La minería canadiense en México:

violencia hecha en Canadá. CIEPAC (Centro de Investigaciones Económica y Política de Acción Comunitaria), mayo número 535.

Merchand, M. (2012). La globalización y el quehacer del Estado en la política económica y sectorial de México. UdG.

Oblasser, A. y Chaparro A. (2008). Estudio comparativo de la gestión de los pasivos ambientales mineros en Bolivia, Chile, Perú y Estados Unidos. Serie 131. División de recursos naturales e infraestructura, CEPAL Santiago de Chile.

Omal (2015). Organización de multinacionales de América Latina. http://omal.info/spip.php?article5666\#

Rodríguez, I. (2009). Más de 70\% de proyectos mineros en el país son de firmas canadienses. Sección de economía, La jornada. http://www.jornada. unam.mx/2009/07/17/economia/

Sistema Integral de Economía Minera (2008).

Svampa, M. y Antonelli, M. (2009). Minería Transnacional, narrativas del desarrollo y resistencias sociales, Buenos Aires, Biblos.

Tetreault; D. (2013). Los mecanismos del imperialismo canadiense en el sector minero de América. Estudios críticos del desarrollo, 3, (4). http://estudiosdeldesarrollo. 